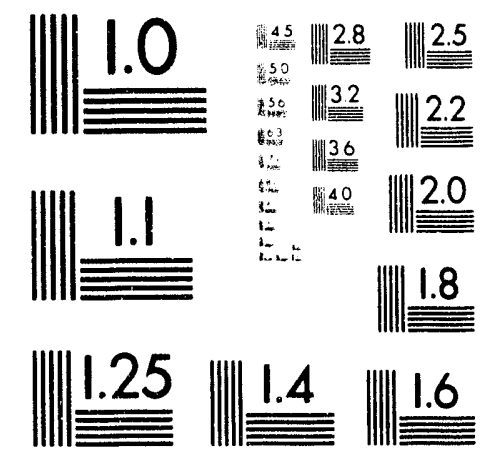



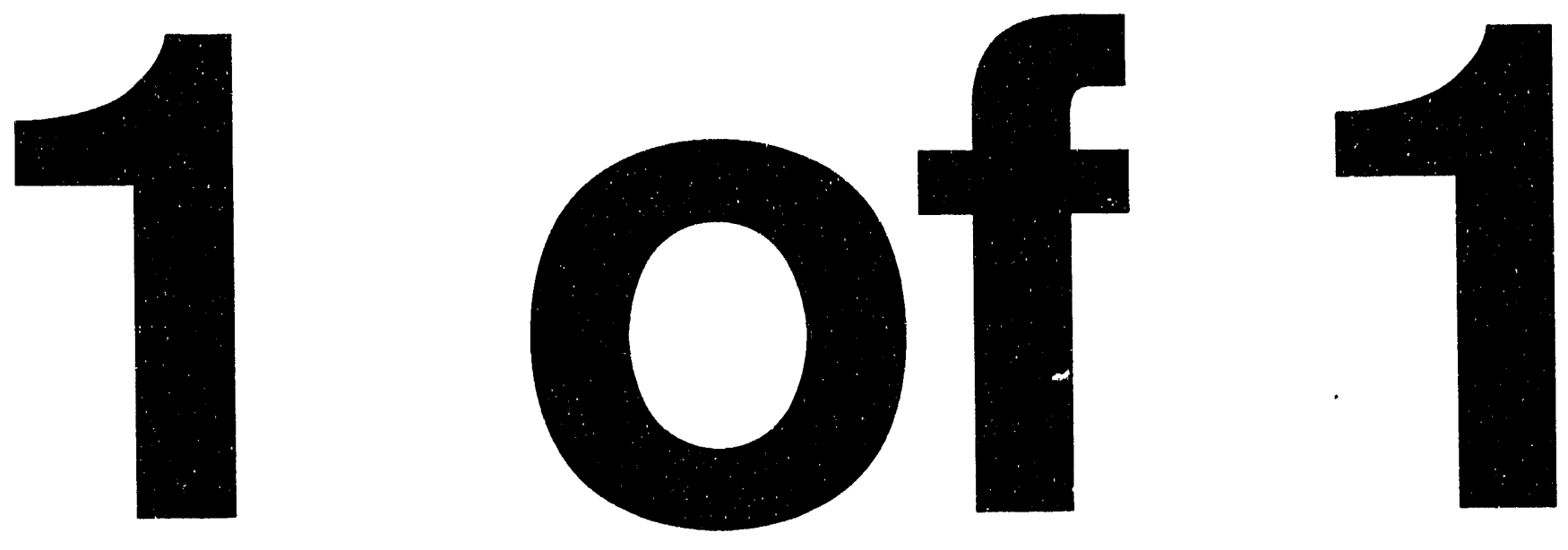


\title{
VIBRATIONAL DYNAMICS IN PHOTOINDUCED ELECTRON TRANSFER
}

\author{
Progress Report \\ Kenneth G. Spears \\ Northwestern University \\ Chemistry Department \\ 2145 Sheridan Road \\ Evanston, IL 60208-3113
}

for Period December 1, 1992 - November 30, 1993

September 8, 1993

Prepared for

The U.S. Department of Energy

Agreement No. FG02-91ER14228

NOTICE

This report was prepared as an account of work sponsored by the United States Government. Neither the United States nor the Department of Energy, nor any of their employees, nor any of their contractors, subcontractors, or their employees, makes any warranty, express or implied, or assumes any legal liability or responsiblity for the accuracy, completeness, or usefulness of any information, apparatus, product or process disclosed or represents that its use would not infringe privately-owned rights.
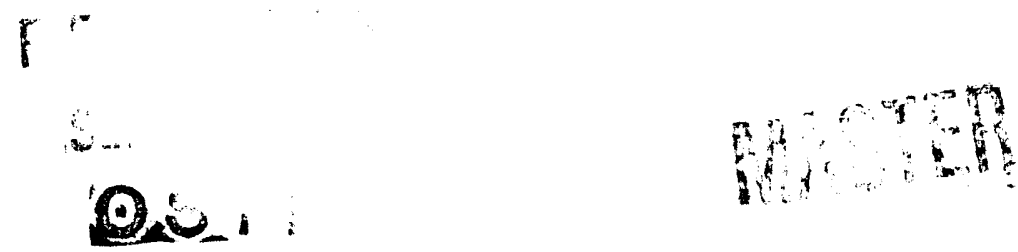
Progress Report for 12/1/92 - 11/30/93 DOE/ER/14228-2

Vibrational Dynamics in Photoinduced Electron Transfer

\begin{abstract}
The overall objective is to perform a new type of measurement for optically excited electron transfer processes that can provide unique experimental insight into the molecular mechanism of electron transfer. The measurements of optically excited electron transfer are done with picosecond infrared (IR) absorption spectroscopy to monitor the vibrational motions of the molecules immediately after electron transfer. Theory and experiment suggest that molecular vibrations and distortions are important controlling elements for electron transfer, and direct information has yet to be obtained on these elements of electron transfer mechanisms.

The second period of funding has been dedicated to finishing technique development and performing studies of electron transfer in ion pair systems to identify if vibrational dependent electron transfer rates are present in this system. We have succeeded in measuring, for the first time, electron transfer rates as a function of vibrational state in an ion pair complex in solution. In a different area of electron transfer research we have proposed a new mechanism of solvent gated electron transfer.
\end{abstract}

\title{
Description
}

The development of picosecond infrared absorption spectroscopy is rather recent, and the PI has been a pioneer in these techniques. The existing apparatus required some modifications and improvements to undertake electron transfer measurements, most of which were completed in the first year with some refinements in the second year. The main goals of the second year of the project were:

1. Perform picosecond IR probing of vibrational states in the electron transfer of ion pairs to identify if vibrational dependent electron transfer is possible in this system.

2. Initiate interpretive work on the transient IR data as well as other aspects of solvent effects on electron transfer related to the general area of ion pair solvation.

At the very end of the first period a postdoctoral associate, who was hired for this project was released to another position. The project has been sustained by a fifth year student, Steve Arrivo, although overall productivity has been lost due to the need for a personnel change. Between March and July a series of equipment breakdowns and part replacements has caused significant loss of experimental time; however, waiting time was used to plan and implement equipment improvements to allow easier implementation of widely variable wavelengths for pumping the charge transfer band. A new postdoctoral associate, Xiaoning Wen, who received a Ph.D. in related picosecond laser work from The University of Illinois has joined the group in July.

\section{Transient IR probing of electron transfer in ion pairs}

The experiment uses visible excitation pulses to initiate an electron transfer process. This starts the "molecular clock", and the subsequent events can be monitored spectroscopically by pulses of infrared radiation. The essential experiment is to tune to a single infrared wavelength and then set a time delay between pumping with a visible pulse

\section{Page 1}


and probing the absorption of an IR pulse. A series of time delays is scanned by a mechanical stage to give a time dependent picture of molecular events for up to $20 \mathrm{~ns}$. A new wavelength of IR is then selected to create another time scan, and a spectrum is built up with a series of scans.

The electron transfer (ET) process for ion pairs in solution is a case where optical excitation of a bimolecular ion pair in solution initiates ET. This type of ET involves direct optical excitation of a charge transfer excited state of the ion pair, and the resulting radical pair can then undergo thermal back electron transfer. The solution structure of the ion pair $\left\{\mathrm{Cp}_{2} \mathrm{Co}^{+} \mathrm{Co}(\mathrm{CO})_{4}^{-}\right\}$is similar to crystal structure in lower dielectric solvents. The interaction of cobalticinium $\left(\mathrm{Cp}_{2} \mathrm{Co}^{+}\right)$is sufficient to distort the tetrahedral structure of $\mathrm{Co}(\mathrm{CO})_{4}{ }^{-}$in the ion pair and create a new charge transfer $(\mathrm{CT})$ band that peaks at $520 \mathrm{~nm}$ and tails to $750 \mathrm{~nm}$. The primary electron transfer occurs upon optical excitation of this CT absorption to form a neutral pair, where the IR spectrum of $\mathrm{Co}(\mathrm{CO})_{4}$ radicals is distinct from the ionic species, which is important for our experiments.

The first surprising result of our transient experiments is that the optical excitation of ET gave the species $\mathrm{Co}(\mathrm{CO})_{4}$ in very vibrationally excited states, especially in the $\mathrm{CO}$ stretching modes (population in 0,1,2,3 quanta). The Franck-Condon factor analysis of how so much energy ends up in these modes will be done in the next months; we will use theoretical models, IR spectra and Raman studies of the ion pair (Raman uses the new DOE sponsored Raman facility in collaboration with Joe Hupp).

The vibrationally excited $\mathrm{Co}(\mathrm{CO})_{4}$ species shows decay rates from back ET and intramolecular vibrational relaxation on potentially fast time scales. If the neutral pair diffuses apart to some degree, then the back ET is slowed and decay includes diffusion processes of nearly caged species. The experimental data in dichloromethane show a series of decays with the $v=3$ state decaying in $<1$ ps with $v=2$ of $3 p s, v=1$ of 7 ps and $v=0$ of about 18 ps. The data shows that the $v=0$ state has some long component from the neutral pair separation, but the fast decays are due to back ET.

The experiments monitoring the ion pair concentrations also show extensive vibrational excitation ( $\mathrm{v}=0$ to $\mathrm{v}=3$ ). The major component of risetime is about $1 \mathrm{ps}$, but we expect that the risetime would be complex since all states of the neutral pair could have some Franck-Condon probability to decay into any given vibrational state. These data confirm that vibrational excitation is maintained in the back ET, and the decay of vibrational energy in the ion pair from intramolecular processes is not as fast as the back ET rates.

The data analysis thus far shows that there are different ET rates for different degrees of vibrational energy content in the neutral pair. This is the first demonstration of such an effect in the history of electron transfer research, and it will have major significance in testing the molecular details of ET processes. The theoretical significance of this result requires us to understand the vibrational states of the ion pair and the neutral pair.

Current work is repeating some of these results with different experimental parameters to prevent any artifacts from coloring interpretive details. We will use different solvent polarity to slightly slow down the back ET rates for more precise measurements of the kinetics and thereby improve our ability to test theoreticil models. The essential test is to understand if the rate variations with vibrational state need to invoke vibronic coupling models, which would be the first time such a mechanism has been proven to be part of ET in metal-metal systems. Complete experimental tests will require excitation at multiple wavelengths and variation of the cation structure so that the mechanism is understood on a molecular basis. Other molecular systems will need to be found with similar mechanisms to prove the generality of the effect for covalently linked metal ion systems. Some candidate molecules are being evaluated through collaborations with A.B. Bocarsly and J. Hupp. The overall prognosis for the next year is that this type of molecular system is sufficiently rich in

\section{Page 2}


details that we will not have sufticient resources to work on organic electron transfer systems, such as those involving porphyrins.

\section{Solvent Gating Effects in Electron Transfer}

The general problem of how solvent can influence electron transfer rates involves many aspects of current research in electron transfer. We have been considering different mechanistic ideas while reviewing the literature and have come up with a new mechanism of solvent gating. Data to support this idea was found in a body of unpublished data obtained 4 years ago by undergraduate research students and a postdoctoral (non-current research grant). A publication has been submitted to the Journal of Physical Chemistry titled Solvent Gating of Intramolecular Electron Transfer.

Abstract: The rates for ionic photodissociation of malachite green leucocyanide to form cyanide ion and a malchite green carbonium ion were measured as a function of solvent and temperature. The observed rates in mixtures of polar and non-polar solvents all had an activation eis rgy of about $1 \mathrm{kcal} / \mathrm{mol}$ for a wide range of dielectric constants. This dissociative intramolecular electron transfer (DIET) is ususual because it is the first example where solvent configurational entropy changes are required to enable a large amplitude molecular distortion that has a nonadiabatic electron transfer and ionic dissociatio 2 . This solvent gated electron transfer mechanis $\mathrm{rn}$ is supported by analysis of the pre-exponential and activation energy trends in dipolar aprotic solvent mixtures and alcohol solvents. The large amplitude motion is not separately measureable due to the slow rates, but viscosity effects on both the pre-exponential and the activation energy are analyzed to demonstrate consistency with a barrierless diffusion model having a structural dependence of electron transfer rate. The rate has an inverse dependence on viscosity raised to the 0.53 power.

\section{Summary:}

1. The picosecond IR measurements of optically excited electron transfer in an ion pair has resolved back electron transfer rates as a function of vibrational state. These are the first measurements of vibrational effects in electron transfer and will be important for understanding the molecular basis of electron transfer in metal-metal coupled systems.

2. The interpretation of rates for dissociative intramolecular electron transfer (DIET) demonstrated a new solvent gated electron transfer mechanism, where solvent configurational entropy changes are required to enable a large amplitude molecular distortion that has a nonadiabatic electron transfer and ionic dissociation.

\section{PI Time on the Project}

The PI has spent one summer month and about $10 \%$ of other time on the project.

\section{DISCLAIMER}

\footnotetext{
This report was prepared as an account of work sponsored by an agency of the United States Government. Neither the United States Government nor any agency thereof, nor any of their employees, makes any warranty, express or implied, or assumes any legal liability or responsibility for the accuracy, completeness, or usefulness of any information, apparatus, product, or process disclosed, or represents that its use would not infringe privately owned rights. Reference herein to any specific commercial product, process, or service by trade name, trademark, manufacturer, or otherwise does not necessarily constitute or imply its endorsement, recommendation, or favoring by the United States Government or any agency thereof. The views and opinions of authors expressed herein do not necessarily state or reflect those of the United States Government or any agency thereof.
} 

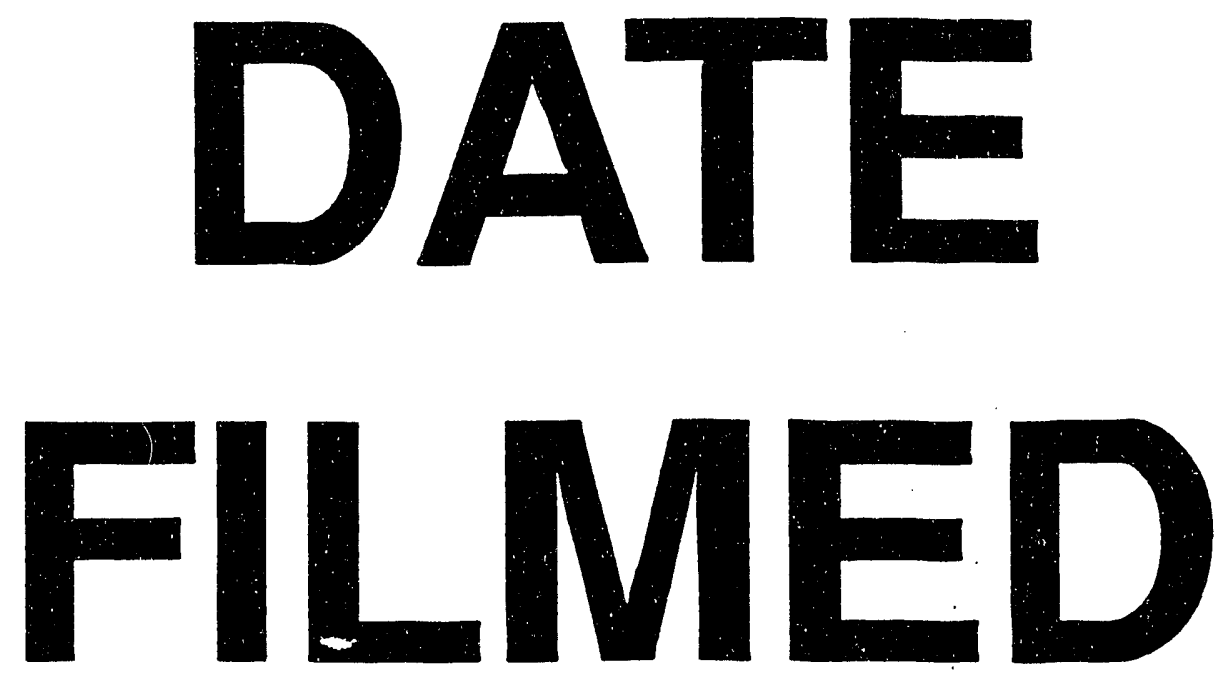

$10 / 13 / 93$
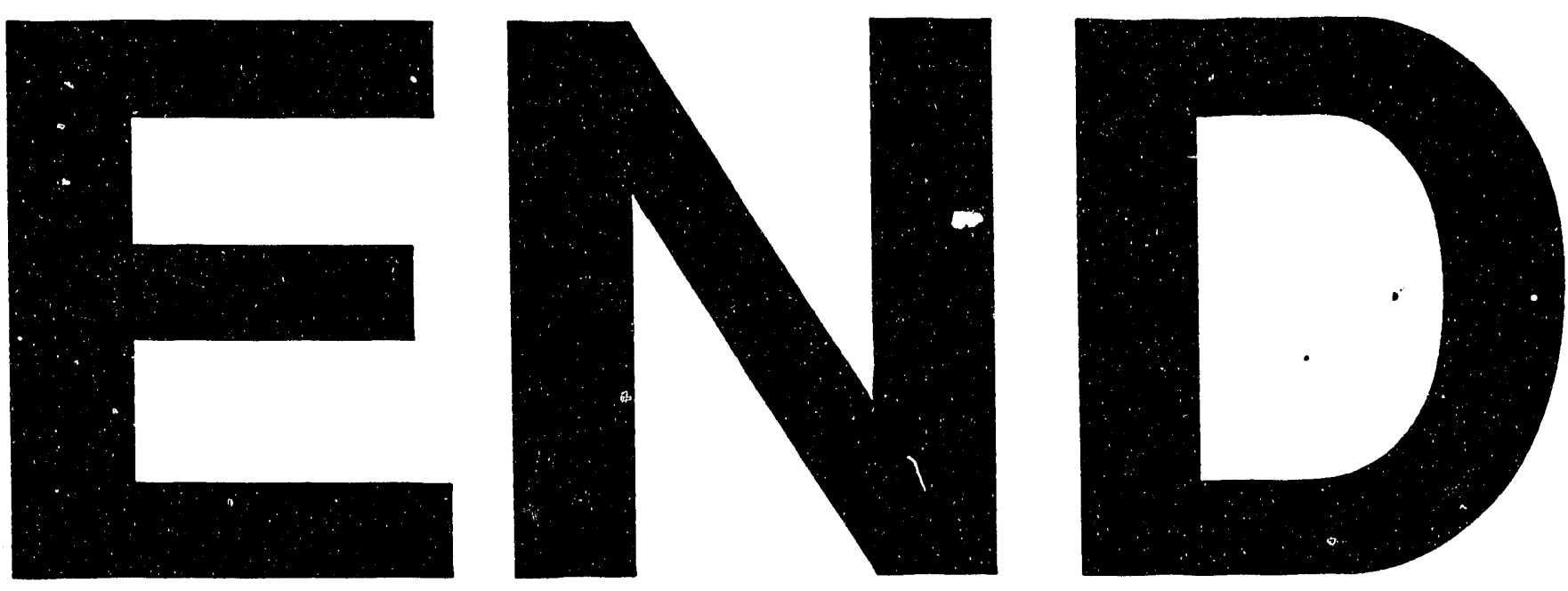


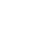

